\title{
PENSAR DESDE LA PASIÓN. FILOSOFAR CON VLADIMIR JANKÉLÉVITCH
}

Think from passion. Philosophize with Vladimir Jankélévitch

Domingo Fernández Agis*

Resumen

El pasado 6 de junio se cumplieron 30 años de la muerte del pensador Vladimir Jankélévitch, acaecida en Paris en 1985. Se trata de un lapso temporal considerable, casi un tercio de siglo, que nos permite realizar un balance de la actualidad y previsible pervivencia en el futuro de su obra. En el presente trabajo pretendo realizar un breve recorrido por algunos de los temas filosóficos que abordó en sus obras más relevantes, reivindicando la vigencia de su pensamiento en este siglo XXI, que va abriéndose paso entre profundos dramas humanos. En cierta forma, tan complejas circunstancias constituyen otras tantas proyecciones de las que Jankélévitch conoció a lo largo de su extraordinaria peripecia vital. Con todo ello como telón de fondo, focalizaré mi atención en cinco grandes asuntos: el estatuto del saber filosófico, la ética como base de la relación con el otro, el amor, la muerte y la búsqueda de la pureza.

Palabras clave: Jankélévitch, filosofía, ética, amor, muerte, pureza.

Abstract

On June 6 the 30th anniversary of the death of Vladimir Jankélévitch, happened in Paris in 1985. After a considerable time lag, almost a third of a century, allows us to take stock of the present and foreseeable future survival of his work. In this paper we try to provide a brief overview of some of the philosophical issues addressed in his most important works, vindicating their importance thought this century, which are presented through deep human dramas. In a way, such complex circumstances are projections of those that Jankélévitch met throughout his extraordinary life. With all this as background, I will focus my attention on five major issues: the status of philosophical knowledge, ethics as the basis for the relationship with the other, love, death and the search for purity.

Key words: Jankélévitch, philosophy, ethics, love, death, purity.

\section{FILOSOFÍA}

¿Merece el resultado de filosofar el empeño y esfuerzo que en esa tarea ha de ponerse? Esta es una cuestión que se plantean desde siempre quienes practican la filosofia o sienten inclinación a aproximarse a su práctica, si bien hoy más que nunca aparece como una pregunta ineludible, debido a las presiones y sacudidas a las que esta disciplina está sometida. Vladimir Jankélévitch se planteó ese problema una y otra vez a lo largo de su vida, en distintas circunstancias pero asumiendo en cada ocasión un considerable riesgo por el solo hecho de afrontarlo tal como lo hizo. Así se pone de manifiesto en La paradoxe de la morale, donde responde a ella evocando la figura de Pascal quien, "al considerar lo irracional de la muerte y el vacío al que estamos abocados, se preguntaba si filosofar valía 
la pena”. Desde ese punto de anclaje en nuestra tradición cultural común, Jankélévitch respondía a continuación sin ambages: "Claro que sí, la filosofía vale la pena a condición de no eludir el problema radical de su propia razón de ser, que siempre es, en algún grado, moral" (Jankélévitch, La paradoja, 12).

La razón de ser de la filosofia se pone en juego cada vez que nos preguntamos por su pertinencia, en un mundo que con tanta frecuencia nos grita que no, que no es necesaria la reflexión filosófica, que ya basta de filosofias. Un mundo en el que, frente a la sinrazón del grito, parece imponerse la razón prudencial del silencio. Frente a él, Jankélévitch ve necesario adoptar, sin pretenderlo en última instancia, una perspectiva moral aunque no moralizante, cree que es necesario ver la vertiente moral que engloba la pregunta por la pertinencia o no del saber filosófico. Porque para él "filosofar se reduce, en suma, a esto: comportarse ante el universo y la vida como si nada fuese por sí mismo; contingencia o necesidad: en lo real hay algo que exige que lo justifiquen" (Jankélévitch, La mala conciencia, 8). Y también nosotros mismos tenemos que justificarnos ante lo real, pues no nos vale el simple estar ahí, la presencia sin otra densidad que la materialidad ni otro sentido que la no ausencia.

Enfrentamiento, por tanto, a la niebla que envuelve nuestra existencia. Entre ella, el filósofo acierta a ver las tinieblas a las que otros llaman luz. Por eso se produce su confrontación con lo establecido, con esa equívoca transparencia, con aquella engañosa luminosidad. Jankélévitch señala, a este respecto, que el "poder de refutar las certidumbres comunes es una especialidad de los filósofos", añadiendo un comentario esclarecedor a propósito de las relaciones entre la filosofia y la ciencia. En efecto, para él, "si las ciencias nos ayudan a tomar conciencia del dato, la filosofia tal vez podría llamarse la conciencia de las ciencias, y la moral, a su vez, no sería más que la conciencia de esta conciencia; toda conciencia encuentra así una conciencia más espiritual que, por así decirlo, es su interior y se ajusta a ella. La moral, como la metafísica, empieza por rechazar evidencias; y la evidencia moral es el placer" (Jankélévitch, La mala conciencia, 9). En efecto, no es fácil poner en cuestión la bondad del placer, su aparente evidencia sensible. Esta se presenta ante quien lo experimenta como una verdad manifiesta, aunque su claridad y distinción disten mucho de la fría evidencia de las verdades cartesianas. En todo caso, se acceda a él o no, el placer generará inquietud, deseo, añoranza, justificación o reivindicación. Así pues, de una u otra forma, el placer conlleva una incitación a la reflexión moral.

En consecuencia, Jankélévitch no ve justificación para que exista inquina alguna de la filosofia ante lo sensible. Sin embargo, considera que el frecuente rechazo de la filosofia hacia la sensibilidad proviene de una aventurada actitud crítica frente a lo dado, de una desconfianza permanente ante todo aquello que parece bien asentado en lo real. "La apariencia es, por tanto, a la vez, lo primero en relación con nosotros mismos y lo que pone en pie el paso subsiguiente; y sin embargo, el ser, sin parecerlo, no sería lo que es, a saber Esse nudum, tenue sustancia y realidad desconocida" (Jankélévitch, Le je-ne-sais-quoi, 5). 
Jankélévitch encuentra en Baltasar Gracián un sugerente punto de apoyo en su aproximación a un filosofar acerca de lo mundano, allí donde la referencia a Pascal había mostrado ya sus insuficiencias. Por eso afirma que este "se compromete más profundamente que Pascal en el juego intramundano", y evoca como antecedentes del autor español tres figuras de orientación intelectual muy diferente, pero que mantienen una profunda conexión en lo que se refiere a sus planteamientos vitales: Cicerón, Maquiavelo y Castiglione. Partiendo de ellos, acaba concluyendo que el héroe "de Gracián es el personaje perfectamente adaptado al régimen de las apariencias, de la doxa y de la astucia. ¡Palabras de seda! Exclama este hombre modernísimo” (Jankélévitch, Le je-ne-sais-quoi, 6).

Siguiendo la estela de esta apreciación, Jankélévitch pone en valor la distinción entre Prudencia y sabiduría, que resulta crucial en el pensamiento del aragonés. "La disyunción peripatética de la Prudentia y la Sapientia, que Platón, el antirretórico, no conoció, se pone de nuevo en obra en el jesuita aragonés, por la constitución de una verdadera técnica prudencial" (Jankélévitch, Le je-ne-sais-quoi, 7). Prudencia y sabiduría se diferencian al tiempo que se complementan entre sí. En cierta manera, la sabiduría conduciría a la prudencia y viceversa. Sin embargo, puede darse una sabiduría imprudente y otra que lleve a los individuos a ponerse en guardia contra la sabiduría. Eso es posible por una buena razón: el mundo no se ajusta al deber ser que el saber descubre en su interior como imperativo racional (Derrida, Une certaine, 89). Lo real no es racional. La utopía hegeliana podría ser la entrada al paraíso o el preludio de las más horribles pesadillas, pero no se ha cumplido jamás.

La astucia es la regla a seguir en una sociedad en la que el posmodernismo, que hace mucho dejó de ser una episódica moda cultural, se ha inscrito en el contenido mismo de lo real. Como sucedió de forma nítida en la sociedad del Barroco, el individuo esconde hoy su verdad tras diversas estrategias de simulación. Ha de hacerlo si quiere sobrevivir en una realidad colectiva en la que el simulacro ha alcanzado su máxima expresión. "Haz a los otros lo que no te gustaría que ellos te hiciesen a ti: Gracián habría olvidado añadir esta máxima a los trescientos oráculos de su Oráculo Manual' (Jankélévitch, Le je-ne-sais-quoi, 10-11). En consecuencia, es preciso orientar los esfuerzos a desenmascarar el juego de los otros y disimular, en igual proporción, los entresijos y objetivos de nuestro propio juego. Todo ello, sin ceder jamás a la adulación ni claudicar frente a los diversos recursos de los que se vale la sagacidad del rival para intentar doblegar, de conformidad con sus intereses, la voluntad del discreto.

Las ideas platónicas han perdido su inmutabilidad, adoptan las formas que convenga, proyectadas sobre una pantalla de metacrilato. Lo eterno encuentra su temporalidad, lo inasible adopta la apariencia de lo cercano aunque no se pueda tocar. "Todo sucede como si el hombre moderno descubriese el maquiavelismo latente del platonismo: retiene para sí mismo la refutación del hedonismo, pero la oculta a los demás, no entrega a los otros la verdad que se reserva para sí" (Jankélévitch, Le je-nesais-quoi, 13). Al mismo tiempo, se entrega a un decisionismo en el que la voluntad 
ha de imponer sus condiciones o ser el factor clave para sortear aquellas que se nos imponen desde instancias externas. "La voluntad como el amor, es más fuerte que el remordimiento y hace milagrosamente del pasado un futuro" (25).

El conocimiento implica otra forma de detención de su objeto, dejándolo en suspenso entre el pasado y el futuro, aun sin permitirle asentarse en el presente. Dice por eso Jankélévitch que "todo lo que es cognoscible en el tiempo es inmovilidad. Todo lo que es palpable en el presente es lo que se hace a sí mismo, es pasado o futuro, todo realizado o cosa pendiente de realización. Todo lo que es asignable en la libertad es (en los dos sentidos del término) determinado. Todo lo que es pensable en la muerte es positividad vital" (81).

Puede que sea pobre el resultado de nuestro deseo de conocer. Este quizá tan solo arroje parciales hallazgos que serán cuestionados y superados de inmediato. Pero hay algo bello y valioso en el mismo impulso a conocer, sean cuales sean sus logros. Arte y conocimiento son los frutos más deseados, a pesar de ser, en cierto sentido, poca cosa, casi nada. Jankélévitch pone con frecuencia el ejemplo de la música, pues no olvidemos que fue un gran amante y un profundo conocedor de esta forma de creación artística. Nos dice que

la música, esa muy vana vanidad, ¿no es toda entera un quasi-nihil? ¿Una pompa de jabón irisada que explota apenas se la toca? La música, que no consiste únicamente en la melodía (puesto que el canto desnudo no es nada), ni en la armonización de la melodía, la música a decir verdad no consiste en nada y huye al infinito: siguiéndola penetramos en la región supraespacial y transmundana de la irrealidad, en el País de los sueños y la Patria de las cosas inexistentes (Jankélévitch, Le je-ne-sais-quoi, 83).

Lo que en verdad importa suele ser en realidad algo que tiene una existencia fugaz y evanescente. Consideremos, tras haber hablado del arte y el conocimiento, es decir, tras haber evocado algunos de los terrenos en los que se juega su posibilidad de realización, el problema de la libertad. Para Jankélévitch "la libertad es equívoca y fugitiva hacia el infinito" pero, pese a ello, "la voluntad de querer no puede ser nihilizada". En definitiva, sostiene que "estas dos marcas contradictorias coinciden por la intuición en la simplicidad puntual de un casi nada" (Jankélévitch, Le je-ne-sais-quoi, 261). La libertad también es, por tanto, presque rien, casi nada. Pero sobre ella pivota la posibilidad de una existencia auténtica, pese a que no encontremos con facilidad anclaje firme para apoyar o justificar nuestra acción. Es lo que ocurre cuando, en el contexto de la pérdida de confianza en la solidez de la racionalidad, hablamos de la libertad de pensamiento y de la libertad de expresión. "Decir lo que se piensa -he aquí toda la fórmula de la Franqueza-. La franqueza se convierte en un problema en la medida en que pierde la confianza en el logos" (262). Por tanto, no es solo problemática por la desconfianza y prevención en relación con los otros.

Sin poder remitirnos a una confianza en el logos que hoy es tan dificil de sostener, hemos de actuar y dar razones de nuestro actuar. Por ello, "la conciencia en 
realidad se encuentra atrapada entre dos contradicciones: o el Bien, obligado a ser bueno a cualquier precio, se negará a sí mismo; o el Bien, más atento a la supervivencia en general que a permanecer como bueno en stricto sensu, será previsiblemente infiel a sí mismo" (Jankélévitch, Traité des vertus, 278).

La cuestionada existencia del logos afecta como es obvio a la existencia y consistencia de la verdad. Por otra parte, como Foucault nos ha enseñado, la construcción de la verdad es una necesidad ineludible para el poder (Foucault, Microfisica, 180-181). Ninguna estructura social ni ningún individuo pueden funcionar al margen de relaciones de poder y es en el seno de ellas donde se define y construye la verdad (Foucault, la critique, 47). Por ello, la verdad no puede pensarse como algo abstracto, singularizado e independiente de las relaciones de poder. Jankélévitch ha insistido en esto al afirmar que "la verdad concebida aisladamente es una verdad sin logos, una verdad gramatical, una verdad mentirosa" (Jankélévitch, Traité, 279). Para él, este tipo de verdad nos remite a los sofismas que, como es sabido, siempre contienen algo de verdad a pesar de ser falsos en aquello que concluyen. A estos, "en ningún lado se les sorprende en flagrante delito de superchería, y sin embargo es necesario que estén en la no verdad, ya que su conclusión es tan contradictoria como el suicidio de la libertad en nombre de la libertad absoluta, o la suspensión del agente moral en el nombre del ascetismo" (Jankélévitch, Traité, 279).

Por lo demás, es muy frecuente escuchar la expresión "tomarse las cosas con filosofia". Dicho de otro modo, mucho se ha hablado de resignarse ante la realidad, asumir los hechos y negarse a transformar nada. Parece que pensara en ello Jankélévitch cuando afirmaba que "la resignación al absurdo, es decir, la imposibilidad necesaria, es la filosofía misma" (Jankélévitch, Traité, 580). Pero ¿acaso no es más filosófica la rebelión frente al absurdo? Nos negamos a resignarnos frente al absurdo de la existencia. De ahí proviene el impulso filosófico determinante.

\section{ÉTICA Y ALTERIDAD}

Habría un posicionamiento previo a la elección moral, pues antes de orientar una acción en uno u otro sentido, el sujeto moral tendría que haber optado por intentar superar el egoísmo, poniendo el bien del otro por encima del bien propio. Es este requisito de la elección previa lo que convierte la moral en un territorio utópico. Afrontar la entrega completa al otro, jugarse uno la vida para defender la vida de otro, de una multitud sin rostro, de otros a los que no nos une ningún lazo personal, tal como hizo el propio Jankélévitch al enrolarse en la resistencia contra el nazismo, constituye la expresión más alta del sentido ético que puede impregnar hasta lo más profundo la existencia humana. Pero también puede ensayarse tal entrega en el territorio del deseo, tanto o más que como puede hacerse en el territorio de la realidad. Sin embargo, "la preferibilidad incondicional del otro no puede justificarse de manera racional. La vida del otro tiene un precio infinito, sea quien sea ese otro, independientemente de las cualidades, talentos o competencias de ese otro; tengo que consagrarme a él solo porque 
es otro; porque no es yo" (Jankélévitch, La paradoja, 56). Al igual que Lévinas, él sabe bien que en este insondable enigma puede encontrarse una de las fuentes del sentido de la existencia (Lévinas, 211), no duda que "es este inexplicable lo que explica lo inexplicable de la segunda paradoja, la absurdidad de vivir hasta morir por ello. El hecho de la alteridad no es siquiera, hablando con propiedad, la razón abstracta que explica el amor" (Jankélévitch, La paradoja, 56). Pero ¿qué puede explicar el amor? ¿Qué puede justificarlo? Altruismo y narcisismo se mezclan en él en dosis desiguales, las relaciones amorosas tienen una geometría variable, una distribución asimétrica en la que el altruismo ha de pesar siempre más que el narcisismo, sin que este último pueda estar del todo ausente, pues su carencia absoluta también acabaría con el amor.

La filosofia tiene que ayudarnos a vivir, en lugar de ser una fuente de continua insatisfacción y perpetuo reproche. Para él, esto conlleva asumir que hemos de enfrentarnos al enigma de lo absoluto en terrenos tan espinosos como el de la moral. En efecto, "lo-que-debe-ser está hecho para realizarse un día en la tierra. Así pues, el valor es ciertamente la razón de ser del ser, puesto que sin valor el ser no merecería siquiera existir, no tendría derecho a la existencia; puesto que sin el valor, el ser no sería lo que es" (Jankélévitch, La paradoja, 101-102). En suma, a su juicio, "la vida no vale nada sin las razones de vivir; pero ¿qué son razones de vivir sin una esperanza de vida, sin una vida al menos virtual y futura? Y el ser, a su vez, es también la razón de ser del deber-ser, razón de ser no racional o nocional, razón de ser no jurídica e ideal, sino vital" (101-102).

La vida necesita razones, por más que digamos lo contrario en momentos de desesperación absoluta y negación nihilista, necesitamos poder dar razón de la vida, intentamos una y otra vez ser capaces de vivir envueltos en una racionalidad que, como quería Ortega y Gasset, ha de ser razón vital (Elorza, 140).

La moral plantea retos y exigencias pero, frente a ellos, frente a los imperativos que suscitan, abrazar el relativismo es la más seductora tentación. Podemos decirnos a nosotros mismos que la voz de la moral no es clara (Heidegger, 293), que no clama en el interior de la conciencia con la fuerza debida, que todo depende del punto de vista, que mejor no poner el acento en la posibilidad de la verdad sino en la probabilidad del error moral. Sin embargo, para Jankélévitch hay en la exigencia moral una ambigüedad que en realidad resulta ser no ambigua. A su modo de ver, la exigencia moral se sitúa entre dos extremos, un punto en el que la "exigencia infinita del deber" y la defensa de los "derechos imprescriptibles" pueden llegar a neutralizarse entre ellos, donde lo opaco puede llegar a mostrarse luminoso, "consumido por la llama del amor y acariciado por su luz", donde se da la oscilación permanente entre dos exigencias. Para él, es "la ambigüedad misma de estas cuatro ambigüedades la que da la consistencia inconsistente, la evidencia tan inevidente, tan decepcionante $\mathrm{y}$, sin embargo, indestructible e infinitamente renaciente del imperativo moral. Un modus vivendi se establece entre el agente moral y esa miseria interior que es la incompatibilidad irreductible del ser y del amor"' (Jankélévitch, La paradoja, 121). 
El deber moral emerge en el ámbito de la autoexigencia, allí donde lo que se busca va más allá de la afirmación de lo singular (Plourde, 409). También exige la puesta entre paréntesis del interés personal y la asunción comprometida de la obligación hacia lo colectivo. Hacia un horizonte en el que el otro se configura como los otros y abre el camino a un nosotros.

Un menos que es un más: tal es el deber. Y, ante todo, un menos: ya que sus áridas e ingratas tareas exigen el sacrificio de mi interés propio y se deducen de mi tiempo de placer y de mi libertad. Tus derechos retornan a ti, te pertenecen, pero su defensa me incumbe a mí y, bajo esta forma, constituyen lo más sagrado de mis deberes; hacer valer mis propios derechos no es mi función, ni reivindicar lo que se me debe, ni siquiera hablar de ello -ya que la conciencia de mi propio derecho, considerada reflexivamente y en primera persona, nunca es moral; permanece prisionera del interés y de la sordidez-. El hombre del deber no trabaja para justificar más o menos hipócritamente su propio derecho o su propia ambición, está más bien para santificar la felicidad de los demás (Jankélévitch, La paradoja, 231).

El deber conlleva, por tanto, sacrificio personal, relegación de lo propio y entrega al otro. En ese contexto se concreta la experiencia del reconocimiento, pero también lo hace en muchas ocasiones la mala conciencia. A ello dedica Jankélévitch un brillante trabajo, La mauvaise consciensce. En él sostiene, partiendo de un peculiar reconocimiento del carácter ambiguo de lo que denominamos mala conciencia, que esta no es otra cosa que una expresión de la conciencia general o del espíritu, empleando así un término más ambiguo aún. Es "el acto por el cual el espíritu se desdobla y se aleja a la vez de sí mismo y de las cosas es un acto más bien, la 'toma de conciencia' no designa un acto distinto, sino una función en la que toda el alma figura en cierto grado y que es propia de la actitud filosófica" (Jankélévitch, La mala conciencia, 7).

El conflicto entre intereses individuales y sociales puede resolverse con la introducción de un elemento, el amor, al que tantos poetas, pero también grandes pensadores como el joven Hegel, atribuyeron un enorme poder reconciliador (Lukács, 219). El amor puede hacer viable la reconciliación del individuo y la sociedad, pero asimismo la del ser humano consigo mismo. Él se pregunta si los intereses particulares de los amantes falsifican o no la abnegación mutua con la que, según es común suponer, deben entregarse el uno al otro. Y concluye que, aunque cierta forma de egoísmo pueda ser acorde a la buena voluntad, en sentido kantiano, nos alejaría de la posibilidad de una entrega sin condiciones. Por ello, dice que "se le parece como una muñeca a un ser vivo; jsolo le falta lo esencial! Falta el amor que es el alma de la inspiración virtuosa: aparte de ello, tiene todas las apariencias" (Jankélévitch, La mala conciencia, 12).

Mediante el concepto amor, se alude a cuanto impregna de emociones y sentimientos positivos la interacción social. Pero el recurso a dicho concepto, pone asimismo de relieve las dificultades que entraña el trabajo de la conciencia especulativa, pues el riesgo que esta comporta es ofrecernos como real algo que no pasa de ser un 
simulacro privado de fuerza vital. Siempre en guardia contra lo que denomina "la conciencia especulativa", denuncia que esta se ocupa ante todo de "destilar sus conceptos para que no sean más que ellos mismos y sin mezcla con ningún otro, en administrar un vacío, por minúsculo que sea, entre el sujeto y el objeto". Frente a ello, se esfuerza en mostrar que "la dificultad del conocimiento de sí mismo es, por tanto, una simple dificultad psicológica: ¿cómo pensar, aparte del yo, en un objeto tan próximo a ese yo? Entre el mayor alejamiento que es condición de toda visión serena, y la mayor proximidad, única que nos da imágenes detalladas, individuales y flagrantes, arrebatadoras de relieve y de vida, ¿cuál es la distancia 'óptima'?' (26).

Distancia indica separación, pero también proximidad. Finis es el término latino para designar la frontera, pero a la vez significa territorio. La distancia introduce en la conciencia lo que hay detrás de ambas acepciones. Contrapone la conciencia especulativa, entendida como conciencia contemplativa, a la "mala conciencia", que arrastra al individuo a una verdadera condena, al acusarse a sí misma y sucumbir al "horror de sí misma". Por ello afirma que, una vez instalados en ella, "ya no es posible una retirada estratégica, y la conciencia, arrinconada en las últimas trincheras, privada de ese 'divertimento' que, según Pascal, le evita pensar en sí misma, la conciencia se encuentra en lucha consigo misma; y como no puede ni mirarse a la cara ni desviar la mirada, se encuentra atormentada por la vergüenza y los remordimientos. Uno de los elementos esenciales de la mala conciencia es esta horrible soledad de un alma que ha debido renunciar a toda diversión y que experimenta una especie de horror pánico o de agorafobia moral al sentirse desnuda en presencia del único testigo al que no puede ocultar nada, puesto que ese testigo soy yo mismo" (28-29).

En efecto, habría una mala conciencia tras todo ejercicio de ocultamiento que el sujeto emprende para ponerse a salvo de la culpa, para salvaguardarse del remordimiento, para no apesadumbrarse bajo el peso del pasado y el agobio de la irresolución. Jankélévitch distingue entre el arrepentimiento y el remordimiento, recurriendo para ello a considerar que lo que separa a ambos no es una simple diferencia de intensidad. Considera así que, lejos de ser un "remordimiento crónico", "el arrepentimiento es lo contrario del remordimiento", porque el remordimiento remitiría a "la falta misma, la falta no resuelta, que se ha hecho consciente y, por ello, dolorosa; el pecado se conoce como pecado sin dejar, empero, de ser él mismo, de suerte que se puede decir del remordimiento que es, a nuestra voluntad, el sujeto o el objeto, el pecado o la conciencia del pecado, o el pecador, ya que todas esas cosas no forman más que una sola. El remordimiento, el sufrimiento eterno y puro, en tanto que no desemboca más que en sí mismo, parece por completo insoluble. El arrepentimiento, por el contrario, es una solución; aquí el acento se desplaza de la falta propiamente dicha, al yo culpable" (79).

Así pues, en el arrepentimiento podemos ver, con Jankélévitch, una solución, una vía de escape al atormentado deambular de la conciencia en el interior del remordimiento. Por otra parte, el remordimiento también se contrapondría a la justicia. De hecho él considera que es muy injusto, pues por el modo de pensar que el 
remordimiento impulsa, pretendemos convencernos de que "sufrir es acumular una especie de crédito". Por lo demás, el remordimiento no conllevaría una suerte de pago de la deuda contraída o voluntad de perfeccionamiento, aunque suponga un castigo. Para él, el dolor que provoca el remordimiento se repliega una y otra vez sobre sí mismo, sin proyectarse en nada positivo. Se parece al imperativo categórico kantiano, pues "este sufrimiento es desinteresado, como el amor es imprescriptible: puro amor, puro sufrimiento de la desesperación; uno y otro son tan inútiles como desproporcionados a su causa. También el remordimiento podría decir su falta: porque es ella, porque soy yo. Tal es la ley moral: tan santa, tan preciosa que quienes no han querido amarla por sí misma deberán sufrir por ella de forma gratuita. La mala conciencia no lo hace a propósito; como no ha podido ser desinteresada por amor, será desinteresada a regañadientes, por violencia y angustia" (88).

Aspecto crucial en la experiencia del arrepentimiento es la autopercepción del sujeto en la continua reiteración mental del acto y su acompañamiento de la experiencia colateral de la vergüenza. Para él, "la vergüenza lucha contra la falta como la fiebre lucha contra la infección" (106). Siguiendo esta analogía, nos dice que, al igual que el proceso febril prueba que el organismo está dispuesto a resistir y a luchar contra la infección, la vergüenza muestra que el individuo aún siente pudor y que, por tanto, tiene una conciencia moral. En efecto, "no nos ruborizaríamos si no tuviésemos mala conciencia, pero no tendríamos mala conciencia si no hubiésemos guardado el sentimiento de nuestra dignidad y esta especie de orgullo delicado y secreto que ennoblece a tantas conciencias caídas" (106). En efecto, a cierto sentimiento de dignidad puede el ser humano agarrarse aun en las peores circunstancias.

En consecuencia, esta dolorosa experiencia es, al mismo tiempo, esperanzadora. En ella hay autoafirmación y también afirmación de algo que trasciende los límites de la subjetividad: el bien. Sin embargo, no por ello deja Jankélévitch de reconocer que "el mal es más evidente que el bien, más envolvente, más voluminoso; entre el bien y el mal, es el bien el que deja duda" (149).

En su Traité des vertus, Jankélévitch habla de un notorio desequilibrio entre los efectos que tiene la conciencia de la experiencia placentera y su paralelo contrapeso, referido a la experiencia del dolor. Jankélévitch habla, en este sentido, de una disparidad en los efectos de ambas formas de conciencia. Ya que "la conciencia del placer disuelve el placer, mientras que la conciencia del dolor agrava el dolor y lo hace más pesado; más aún, el dolor que no es soluble en la conciencia no es quizá sino esa conciencia misma, la triste mala conciencia del cuerpo o del órgano desgajado" (Jankélévitch, Traité, 6).

Es más profundo y valioso lo que el individuo puede extraer de la conciencia del dolor, que aquello que hipotéticamente pueda obtener de la conciencia del placer. En este sentido, resulta muy elocuente la comparación que Jankélévitch realiza entre el uso del discurso, en términos generales, y la específica referencia discursiva al amor. Su planteamiento parte de señalar el automatismo de los procedimientos discursivos, subrayando cómo estos sepultan las "intuiciones motrices" iniciales y las 
intuiciones vinculadas a la evocación de la experiencia amorosa, "así, del placer no se escoge en todo momento sino el envoltorio retórico" (10).

Escoger el envoltorio y recoger los desechos, esos dos gestos definen a menudo el acercamiento a la experiencia amorosa. Se dice que al empeñarnos en tal acercamiento no hacemos otra cosa que responder a la llamada de la naturaleza, atender a nuestra obligación biológica. Jankélévitch discrepa de forma nítida: "¿La voz de la naturaleza? Pero eso no son más que gritos incoherentes y discordantes, de los que no se desprende ningún imperativo claro" (15). ¿Qué significa esa voz? ¿Hacia dónde nos llama? Jankélévitch sugiere que, de oír algo a lo que podamos dar tal nombre, su significado es confuso y puede empujarnos en cualquier dirección. Incluida la que caracteriza a todo nihilismo paralizador. Por eso ha criticado lo que denomina el "quietismo" de Kierkegaard (24), al tiempo que denunciaba el impulso nihilista que subyace a gran parte del discurso existencialista.

En relación con el asunto del estatuto de la moral frente al derecho, Jankélévitch señala que "la persona no tiene moralmente sino deberes y no derechos: pero de estos deberes de los otros, entre los que figura el de respetarme como yo los respeto, han resultado accidentalmente para mí ciertas libertades, que se encuentran en efecto entre mis derechos y que no tengo más razón para despreciar de la que he tenido para reivindicarlas" (36).

Todo ello nos pone en la pista de un relativismo moral que no abjura de la posibilidad de una moral colectiva, pero que renuncia de antemano a cualquier estrategia que esté orientada a imponerla. Por supuesto que, tal actitud, presupone la renuncia a toda forma de absolutismo y dogmatismo. Basándose en ello, su fundamento último es cuestionado con sugerente habilidad. En ese sentido, Jankélévitch nos dice que "la agonía de Dios durará hasta el fin del mundo, habrá siempre algo que hacer durante ese tiempo, y la conciencia no está próxima a dormirse en su sueño dogmático" (49).

Por otra parte, su reflexión acerca de la moral apunta a hacerse cargo de nociones y planteamientos básicos, que la relacionen con una situación fáctica a la que aún no se ha vinculado en su justa medida, con profundas mutaciones intelectuales. A su juicio, "la noción de conflicto que divide nuestra modernidad nos ha hecho, por tanto, abandonar las grandes esperanzas saintsimonianas de una ética industrial y de una moralización de la técnica" (50). De forma análoga, cuestionará el planteamiento que, desde Aristóteles, se ha hecho de la noción de virtud. Desde esa perspectiva, pone de relieve las aportaciones de diferentes teóricos a partir de la modernidad. Por eso afirma que "Spinoza tiene razón, la alegría no es la recompensa de la virtud, pero es necesario que surja espontáneamente del centro mismo de nuestra buena voluntad" (70). En consecuencia, es preciso que el compromiso con el bien no sea solo intelectual. Ha de implicar de forma vital al individuo, entrañando de esa manera un compromiso emocional.

En esa misma línea, viene a señalar que en Kant se observa la ruptura del vínculo imaginario que la cultura pagana estableció entre la prosperidad y la virtud, que de alguna forma se había transformado bajo la interpretación de Spinoza, quien 
consideraba que es la propia virtud, "lo que es la felicidad misma, siendo en sí su propia recompensa" (134).

Recogiendo esas lecturas críticas del eudemonismo clásico, Jankélévitch afirma que "la virtud no es fuego de paja, el efímero brillo llameante de la emoción, sino más bien la llama duradera de la pasión" (147). Algo que él vinculará, en la línea que hará suya Lévinas, con una ética asimétrica y descentrada, que concede prioridad a la responsabilidad frente al otro (Fernández Agis, Mucho más que palabras, 25-26). Por ese motivo, concluye:

Soy a la vez yo mismo y una imagen de mí reflejada en el espejo del Otro, en la opinión y la estima del Otro, pienso en lo que el Otro pensará y me represento con dulzura, como si fuera él, su deseo y su admiración, al menos en la medida en que estoy convencido de merecerlos; porque soy este Otro, soy no-yo, y el Otro es la ficción que me sirve para decir todo lo que no puedo decirme a mí mismo (Jankélévitch, Traité, 749).

El Otro es también, como vemos, un modo de evitar el silencio de uno mismo ante todo aquello que nos produce un dolor que no quisiéramos asumir (Lévinas, 207).

AMOR

Su punto de partida al hablar de la experiencia amorosa es afirmar que subyace al amor un imperativo ético altruista. En ese sentido, para él, el impulso que conduce hacia el amor carece de motivación y, en virtud de ello, por tal carencia de fundamento motivacional, tiene un carácter categórico.

Te amo porque eres tú... ¡Lo cual, evidentemente, no es una razón! En el mejor de los casos, es una mala razón. O simplemente: amo sin razón. O mejor aún: ¡amo contra toda razón! Amo porque amo... No hay por qué. En general, se reconoce la sublimidad del sacrificio por el hecho irrisorio de que el amado no merece semejante amor...: entonces, es cuando la piedad pasa a ser más desgarradora (Jankélévitch, La paradoja, 57).

Sin embargo, no puede abandonarse por completo el narcisismo en la relación amorosa (Derrida, Donner le temps, 12). De otra forma no habría modo de contrastar el peso del imperativo altruista. Esto llevaría la relación amorosa a un callejón sin salida y a los amantes a embarcarse en un proceso que puede conducir a su autodestrucción (Fernández Agis, En torno al amor, 31-32).

No obstante, hay un potencial de superación de todo antagonismo en la afirmación amorosa, que puede ser tanto confirmación del otro como afirmación de sí. En efecto, es la reciprocidad de la relación amorosa lo que permite superar, siquiera sea de forma fugaz, la aparente e irreductible polaridad de la existencia humana. Por otra parte, también es en la reciprocidad -según Jankélévitch- donde el ser se manifiesta en su plenitud. 


\section{Domingo Fernández Agis}

Amar hasta morir por ello puede tener dos sentidos, el uno sublime, el otro trivial, y uno de los dos sentidos es al otro lo que es para Platón la Afrodita urania en relación a la Afrodita casamentera. En el sentido sublime, el no-ser del amor, aéreo como el oxígeno, es más sobre-ser que no-ser; este no-ser, que es sobre-ser, es paradójica e incomprensiblemente una vida; una vida más allá del ser; una vida más amplia que el firmamento estrellado de la esperanza. $\mathrm{Y}$ esta vida, en su intensidad, es la vida afirmativa por excelencia (Jankélévitch, $L a$ paradoja, 102).

El poder unificante, vivificador y de superación que conlleva el amor, está detrás de la realización de muchos imposibles.

El tête-à-tête del amor y la muerte, del deber y la muerte, excluyendo toda verdadera reciprocidad, nos arrincona en un callejón sin salida. El cada-vez-más deja entonces de aparecer como un signo de vitalidad y como un crescendo pasional; no es más que un síntoma de fiebre, y una frenética aucción tropieza en el último momento y en última instancia con la barrera de la muerte. Es el fracaso supremo, la caída final en la nada (Jankélévitch, La paradoja, 107-108).

Sí, la muerte marca un límite, una frontera sin retorno. Frente a ella, cada ser humano consciente define su oportunidad y dibuja como puede el mapa del territorio en el que quisiera proyectar sus esfuerzos (Lisciani, 333).

En él aparece la posibilidad imposible del amor puro como la más obstinada forma de reconocimiento, de afirmación del otro, por medio de la proyección y de la entrega de sí. Pero, en su opinión, el amor desinteresado, sin razón justificatoria, está lejos de ser un mero capricho de los amantes. La búsqueda del amor puro es vivida, por el contrario, como respuesta a una exigencia ética (Fernández Agis, Sofisticados, 5). En última instancia,

nuestro amor es, para la alteridad del otro, un puro amor, porque se dirige a la esencia misma del ser amado. Lo que ama no es tal o cual cualidad eminente en tal o cual persona amada (un don excepcional de esta, un notable talento en aquella), ya que el amor, en tal caso, pasaría en segundo lugar después de la amabilidad y se extinguiría con la cualidad que le dio a luz (Jankélévitch, $L a$ paradoja, 233).

Jankélévitch considera que esta sería una forma menor del amor, una inframanifestación que entraña la no realización plena del mismo, pues responde a una motivación específica y permanece condicionada por ella.

En todo caso, al poder reconciliador de la diferencia y lo disyuntivo, hay que añadir la apertura a la posibilidad de lo posible. Y, junto con esto, claro está, el poder afirmativo del amor. "El amor es 'aquello que dice si' y aquello que responde no al no de la muerte, y que a continuación responde sí al sí, responde afirmativamente a la afirmación y vitalmente a la vida, y se hace eco de la positividad del ser" (Jankélévitch, La muerte, 401). Por otra parte, sostiene que 
el amor, aún más que el alma, da a la pureza su valor y razón de ser, pues es movimiento y no sustancia. Su pureza no es, pues, la de un ser puro de todo ingrediente halógeno: ¿se puede pedir incondicionalmente a alguien que solo sea él mismo, es decir, sin mezcla de ningún otro, en tanto que se ignora lo que es en sí mismo? (Jankélévitch, Lo puro, 235).

Es mucho lo que la realización del amor exige: autoconocimiento, conocimiento del otro, sabiduría en relación con nuestra posición y hacer común en la vida. Ante las dificultades que se presentan a la hora de realizar el amor puro, no ha de extrañarnos su ostensible ausencia. Para Jankélévitch, "la falta de amor y la ausencia de cualquier convicción apasionada explica el gusto de nuestros contemporáneos por el equívoco, el abandono a la violencia y la fobia al rostro" (Jankélévitch, Lo puro, 242). Engaño, autoengaño, hostilidad, imposibilidad de mirar al otro; todo ello convive con nosotros, todo ello nos aleja del amor. Sin embargo, el punto de partida para la realización del amor no es en absoluto una posición inalcanzable. Hablamos, en efecto, del "amor que es una consecuencia de la estima, el amor obtenido sutilizando el placer, el amor que se edifica con sentimientos amistosos que no tendrán jamás el agudo corte de la generosa locura o la bella hipérbole" (Jankélévitch, Traité, 477).

Acerca de ese sustrato, la generosidad y sus formas claman buscando su lugar. "Amar, dar, perdonar, crear - estas cuatro iniciativas designan cuatro formas de inocencia-," Jankélévitch no podía albergar duda alguna al respecto. No obstante, recordando el discurso de Fenelón (Fernández Agis, Sofisticados, 3-4) sobre el amor puro, insiste en que "el amor puro quiere almas simples, es decir, sin pliegue de conciencia, y no retorcidas sobre sí mismas, sino enteramente perdidas y derramadas en su cosa; las almas simples, que son buenas conciencias, van hasta el final sin detenerse en ellas mismas" (Jankélévitch, Traité, 495-496). Por tanto, si un rasgo puede definirlo, este sería la generosidad absoluta y la plena entrega a quien se ama.

\section{LA MUERTE}

Jankélévitch, como hemos visto hasta aquí, jamás ha retrocedido ante las dificultades que conlleva un filosofar abocado al tratamiento de las más grandes cuestiones. De esta forma, en su obra La mort, encontramos una original línea de reflexión acerca de la muerte, en la que ahora vamos a adentrarnos.

Su punto de partida es considerar que "la furtiva muerte no está encerrada en la vida como el contenido en el continente, la joya en un cofre o el veneno en un frasco. ¡No! La vida está a la vez investida y penetrada por la muerte; envuelta por ella de cabo a rabo, empapada e impregnada por ella. El que el ser hable solo del ser y la vida de la vida es debido a una lectura superficial y demasiado literal. La vida nos habla de la muerte, no habla de otra cosa más que de la muerte" (Jankélévitch, La muerte, 66). Buscar un espacio de reflexión en el que abordar este problema, no es una tarea que solo afecte al ámbito de lo teorético. Antes bien, se trata de una realidad presente en lo cotidiano. Sin embargo, las dificultades se hacen presentes a la hora de construir un 
discurso acerca de la muerte. Por ello Jankélévitch señala que "hay al menos tres maneras de eludir el obstáculo de la indecidibilidad: la primera es el eufemismo, la segunda la inversión apofántica, y la tercera, que será la nuestra, la conversión a lo inefable" (Jankélévitch, La muerte, 68). El punto de partida ha de ser, en consecuencia, asumir el carácter inefable de la muerte como realidad, así como la proyección del mismo en el intento de construir un discurso, extremo en el que se manifiesta la imposibilidad radical de decir la muerte.

Sorprende su firme convicción, al orientar sin titubeos su discurso respecto de la muerte en la dirección menos esperable, en aquella que más dificultad encierra. En todo caso, a su juicio, la muerte representa la precariedad e inconsistencia esencial de todo lo humano. Por ello jamás puede apelarse a la muerte buscando un fundamento o un sentido para la existencia. Pero, aun así,

la mortalidad termina por hacer fugaz, poroso, fantasmal, ese devenir privado de antemano de consistencia. La muerte no es del mismo signo ni tiene el mismo sentido que la continuación del ser, sino un sentido y un signo contrarios: contradice esa continuación es el Menos de su Más, la negación de su positividad. La relación de nuestro ser con su propia nada arruina completamente los cimientos de este ser (Jankélévitch, La muerte, 75-76).

Por ello concluirá que es absurdo que, en una reflexión acerca de la muerte, pretenda cimentarse el sentido de la vida. "La muerte tiene tan poco de cimiento, que si hay algo que necesite cimentarse es precisamente ella misma" (Jankélévitch, La muerte, 75-76). En ese sentido, Jankélévitch se aleja de la posición característica de Heidegger en Ser y tiempo (Heidegger, Ser y tiempo, 270). En su opinión, nada podemos sustentar de este absurdo, en este sinsentido que es la muerte. A su juicio, "la muerte cierra todas las salidas y detiene toda futurición. En ningún caso, de ninguna forma, en ninguna circunstancia, bajo ninguna condición, en ningún momento la muerte desmiente su gran rechazo. La muerte no es el horizonte infinito que nos atrae, sino el muro opaco que nos detiene" (Jankélévitch, La muerte, 84).

La apuesta de nuestro pensador es clara, tanto en su dimensión discursiva como en sus implicaciones prácticas. Jankélévitch dio, al respecto, sobradas muestras de coherencia en su vida y su obra, si es que ambas pueden separarse en su caso. Hemos de asumir, en consecuencia, que en la vida hay tanto crecimiento como decadencia. A su entender, la vida posee un sentido, aunque esté infectada por un ineludible sinsentido pues "a medida que el tiempo pasa, el contrasentido del envejecimiento implícito en el sentido aflora cada vez con más insistencia a la superficie del devenir; y lo mismo que el organismo envejecido repara sus pérdidas cada vez peor y compensa de forma cada más lenta los efectos de los traumatismos, así la esperanza optimista, luchando palmo a palmo contra los desmentidos repetidos de manera continua al fracaso y de la decepción, se vuelve cada día más difícil decir por qué se vive, y en vistas a qué, y a qué viene todo esto" (178). 
Jankélévitch habla de la muerte como absoluta certeza, como triste constatación de la existencia de un límite irrebasable. Frente a ella, Dios es el objeto de una apuesta, en la que cada uno sabe lo que puede o no jugarse, en la que es absurdo pretender jugar de farol. Pero nadie debería olvidar que se trata de eso, de una apuesta. En definitiva, desde la posición del ser humano no cabe ir más allá. La cuestión ontológica esencial nos supera y siempre nos superará. Fuera del juego y el acto de apostar, no hay respuesta. Además, es doblemente absurdo intentar buscarla, pues, al hacerlo así, al absurdo de la muerte sumamos el sinsentido de una existencia que da la espalda a sí misma. Es por ello, admite Jankélévitch, que siguiendo una tendencia dificil de evitar, se considera que la luminosa infinitud de Dios es lo único que puede contrarrestar la oscura infinitud de la nada. Sin embargo, "tener que recurrir a Dios para conjurar la nada, ¿no equivale esto a bautizar con un nombre nuestra incertidumbre?". Se aproxima entonces a Pascal, para aludir a los efectos que produce la firme convicción de la existencia de Dios, que se presenta unida de manera inevitable a la imposibilidad de definir cuál es su naturaleza. A pesar de esto, considera que la verdadera raíz de nuestra esperanza está en ignorar cuál será el momento de nuestra muerte. Por eso subraya que

no es a Dios, sino a la Hora incierta a la que debemos la única posibilidad de apertura al porvenir. Pero además la quoddidad de Dios dista mucho de ser tan evidente como la certidumbre de deber morir. Tenemos buenas razones para creer en la necesidad de la muerte, y ninguna para concluir en la existencia de un Dios irremediablemente oculto: esta existencia es objeto de una más que dudosa adivinación. La muerte es una triste certeza, mientras que Dios es una buena apuesta (Jankélévitch, La muerte, 407-408).

La muerte remite al ser humano a un horizonte de realización, en el que su posibilidad como individuo se concreta. Pero, en mucho mayor medida, es aquello que limita o hace imposible ciertas posibilidades. Para decirlo con sus propias palabras, "la muerte permite la realización de nuestros posibles, pero no crea esos posibles. $\mathrm{La}$ muerte, contándonos de forma parsimoniosa los años, impide la realización íntegra de la mismidad, y la mismidad irrealizada se queda fuera y más allá de una muerte siempre prematura" (Jankélévitch, La muerte, 430). Sí, sin duda alguna, se vive siempre a destiempo y la muerte nos alcanza siempre antes de tiempo.

El misterio de la nihilización es por tanto paradójicamente nuestra esperanza, a pesar de que no sea en absoluto una razón para esperar (pues no tiene pruebas ni razones para ello). La consagración del intervalo vivido, consagración que resulta de la muerte, nos remite en definitiva a la vida misma. Pues no hay nada más precioso que la vida. La inminencia de la muerte pone al descubierto este infinito valor del Ser que durante el transcurso de su continuación permanece generalmente insensible (Jankélévitch, La muerte, 430).

No olvida señalar, además, que el valor infinito que concedemos a la vida no depende del tipo de vida que llevemos. Es algo que corresponde a toda vida, sean cuales sean las circunstancias particulares en las que esta se desarrolla. 
LO PURO

Obra cuya claridad es más admirable si cabe, en la medida en que se alza desde un fondo turbio en el que es tan dificil ver con alguna claridad, Le pur et l'impur, es un extraordinario trabajo de autoafirmación. En sus páginas iniciales, Jankélévitch recuerda que las palabras, "¡Soy puro!", constituían el lema "que los difuntos del antiguo Egipto llevaban consigo como viático para el gran viaje". Pero, como él mismo nos hace ver, esas palabras "parecen más bien una protesta o la reivindicación de un estado de derecho". En efecto, son "palabras que quizá son hechos para las momias de las necrópolis, pero que ningún ser vivo se atrevería a pronunciar de buena fe" (Jankélévitch, Lo puro, 7).

La pregunta primera que hemos de hacernos es, a este respecto, cómo caracterizar la pureza. A ella Jankélévitch responde afirmando que "la pureza semeja a la muerte, que también es una especie de pureza y que, para todo nuestro ser, representa lo mismo que la nada para el todo" (9). Una pureza conquistada al elevado precio de la ausencia absoluta, de un vacío que recuerda a la imposible plenitud.

De manera inevitable hay que hablar de la infancia al plantear la pregunta por la pureza. En ese sentido, Jankélévitch nos dice que "la pureza comparte este principio con todas las virtudes frágiles: el niño es la inocencia misma, o la pureza sustancial, pero, por definición, lo ignora; el niño es puro, pero no lo sabe, y precisamente esta ignorancia es su pureza; el adulto consciente lo sabría e incluso lo sabría demasiado bien si lo fuese, ipero justamente porque lo sabe deja de serlo!" (Jankélévitch, Lo puro, 7). La pureza del otro puede ser pensada, la de uno mismo, jamás, pues se esfuma cuando pretende ser consciente de sí misma. La fragilidad de la pureza es tal, que es imposible reconocerse en ella, habitarla de forma consciente, ya que en el momento en que lo hacemos la pureza se desvanece o, si pretende permanecer, se transforma en simulacro.

En cualquier caso, ante el carácter inaprensible de la pureza, es preciso dirigirse a su contrario si queremos aproximarnos a ella. Bien sabe Jankélévitch que es imposible la alusión consistente a la pureza, sin tener presente lo impuro. De esta forma, un filosofar sobre la pureza será imposible de construir sin la descripción de la impureza que acompaña a aquella como ineludible contrapunto. Las manifestaciones de lo impuro se presentan ante nosotros como innumerables. De este modo, en su opinión, todo intento de enunciación de la pureza constituirá una operación análoga a la de la teología negativa, que procede diciendo lo que no es Dios, para ofrecer mediante ello una cierta caracterización de lo que Dios es (15-16).

Es posible, por tanto, una inferencia indirecta de lo que pueda ser la pureza, por medio de la enunciación de lo que la pureza no es. En cualquier caso, las dificultades que plantea su conocimiento llevan a Jankélévitch a afirmar que "la pureza no solo es rara. La pureza es además inexistente; la pureza no es solamente inexistente de hecho o hasta el momento presente, sino que también es imposible que exista aquí o allá bajo 
unas determinadas coordenadas espaciotemporales, que se personifique en Pedro o Pablo. La pureza no existe, y, no obstante, define nuestra vocación" (22). Así pues, no pertenece al ámbito del ser, sino al del deber-ser.

Completando el ciclo de sus consideraciones, Jankélévitch recurre a Kant, para abordar el asunto de la pureza desde un ángulo diferente. De esta forma, aludiendo a una terminología característica del discurso de este pensador, insiste en que "nos contentaremos con decir que la pureza es una exigencia normativa y un ideal regulador que nos sirve al menos para medir y apreciar el grado de nuestra impureza. Nos representamos a la indecible pureza a partir de la decible impureza, pues precisamente la impureza es el objeto de una experiencia físicamente inmediata y positiva" (22-23). En una muestra más de la constante atención a la experiencia concreta que caracteriza a su filosofía, sostiene que "cronológicamente y en relación con nosotros, lo impuro precede a lo puro, como la infelicidad, la insinceridad, la ingratitud, la injusticia y la inmoralidad preceden a sus contrarios positivos justicia, gratitud y sinceridad" (22-23). Con ello viene a subrayar el trasfondo de compromiso y apuesta que sostiene toda su obra y que, en términos generales, es lo único que puede otorgar un sentido a nuestra existencia.

$$
\begin{array}{r}
\text { Universidad de La Laguna* } \\
\text { Facultad de Humanidades. Sección Filosofia } \\
\text { Campus de Guajaras/n.38071 La Laguna, Tenerife (España) } \\
\text { dferagi@ull.edu.es }
\end{array}
$$

OBRAS CITADAS

Derrida, Jacques. Donner le temps. Paris: Éditions Galilée, 1991.

__ "Une certaine possibilité impossible de dire l'événement". En Soussana, Gad (et al), Dire l'événement, est-ce possible? Paris: L'Harnattan, 2001: 79-112.

Fernández Agis, Domingo. Mucho más que palabras. Zaragoza: Eclipsados, 2009.

— En torno al amor. Santa Cruz de Tenerife: Idea, 2015.

_ Sofisticados caníbales. Saarbrücken: EAE, 2012.

Elorza, Antonio. La razón y su sombra. Barcelona: Anagrama, 1984.

Foucault, Michel. Qu'est-ce que la critique? Paris: Vrin, 2015.

—_ Microfisica del poder. Trad. J. Varela y F. Álvarez Uría. Madrid: La Piqueta, 1980.

Heidegger, Martin. Ser y tiempo. Trad. J. E. Rivera. Madrid: Trotta, 2003.

Jankélévitch, Vladirmir. La muerte. Trad. M. Arranz. Valencia: Pre-textos, 2002.

Lo puro y lo impuro. Trad. J. L. Checa. Madrid: Taurus, 1990.

— La mala conciencia. Trad. J.J. Utrilla. México: FCE, 1987.

—_ La paradoja de la moral. Trad. N. Pérez. Barcelona: Tusquets, 1983.

_ Le je-ne-sais-quoi et le presque-rien. Paris: PUF, 1957.

_ Traité des vertus. Paris : Bordas, 1949.

Lévinas, Emanuel. Totalidad e infinito. Trad. D.E. Guillot. Salamanca: Sígueme, 2002. 
Domingo Fernández Agis

Lisciani Petrini, Enrica. "Porque solo somos la corteza y la hoja... Acerca de La Mort de Vladimir Jankélévitch". Logos. Anales del seminario de Metafisica. Vol. 44 (2010): 331-354.

Lukács, Georg. El joven Hegel. Trad. M. Sacristán. Barcelona: Grijalbo, 1976.

Plourde, Simonne. "E. Lévinas et V. Jankélévitch: un 'grain' de folie et un 'presquerien' de sagesse pour notre temps". Laval théologique et philosophique. Vol. 49. No 3 (1993): 407-421. 